\title{
Perspectives in Cross-Cultural Communication: When Sociolinguistics Joins the Discourse
}

\author{
Tangyie Evani Ph.D. \\ Senior lecturer \\ Applied Linguistics \\ University of Dschang \\ Cameroon
}

\begin{abstract}
Language dynamics and interpersonal communication require a close examination of how participants in a communicative art negotiate meanings from shared values in the process of cross cultural communication. A transverse analysis of the situation demonstrates that there is an existence of complex efforts on connecting cultural knowledge to cross-linguistic competences alongside a widening range of communicative exchanges. This paper sets to examine some perspectives of cross-cultural communication in a multi-linguistic setting like Cameroon where many local and international languages are in close contact. The paper equally analyses the pertinence of existing macro sociological concepts as fundamental knowledge traits in literal and idiomatic cross semantic mapping. From this point, the article presents a path model of connecting sociolinguistics to the increasing adoption of a widening range of communicative genre piloted by the on-going globalisation trends with its high speed information technology machinery. By applying a cross cultural analysis frame, the paper will be contributing to a better understanding of the fundamental changes in the nature and goals of cross-cultural knowledge in pragmatics of communication and cultural accept abilities. It emphazises on the point that, in an era of increasing global interchange, a comprehensive inclusive global culture through bridging gaps in crosscultural communication would have significant potentials to contribute to achieving global social development goals, if inadequacies in language constructs are adjusted to create avenues that intertwine with socio cultural believes, ensuring that meaningful and context bound sociolinguistic values are observed within the global arena of communication.
\end{abstract}

Keywords: sociolinguistics cross-cultural communication, customary language, literalisms, linguistic meaning, transubstantiation

\subsection{Introduction}

Talking about the object of communication may seem a down to earth issue to some people who have misconstrued communication to simply talking to one another; The first object of any communicative activity, over and beyond the pleasure it may give in expressing thoughts and feelings, is to serve the purpose of effective communication. This communication should not only take to language in use; it should give us insights to a better understanding of the thoughts and feelings being overtly or covertly expressed. But then if the object of communication is streamed down to understanding the form and meaning, verbal or nonverbal combinations of sociological features to enact and stimulate a sensation, then investigating on the psychology of communication should better start with the analysis of form and meaning in communication.

\subsection{Form and Meaning in Cross- Cultural Communication}

It is true that a cultural language user who masters the other alien language culture can often organise his or her communication art from one cultural form to another very rapidly without thinking about the semantic structure overtly. However, for complicated forms of communication - idiomatic, epigrammatic, and level coded, etc. he/she may not be versed with the imagery and would resort to macro sub structures of the customary language to decipher through subjecting to the intension of the communicative context. Even if one is able to make an adequate communication without detailed analysis of the alien culture, it should be of interest to all social communicators to study the process of cross semantic mapping analysis. Those who communicate across customary language boarders will almost never have problems with these common expressions. They hardly think about the fact that the grammatical form and the lexical choices are so different. 
But as they moved into unfamiliar material, or higher levels of semantic structure with complicated sentences and discourses, there is a tendency for choices of lexical items and grammatical forms in the receptor language to be unduly influenced by the lexical items and grammatical forms of the source language. The result will be forms which sound strange and foreign to speakers of the receptor language. For example a German speaker may say in English "The child has fever, it is ill" instead of "the child has fever, he/she is ill" because of the influence of German "Das kind hat fieber, es ist krank".

In English there need to be an article "a" before fever and child is referred to by a masculine or feminine pronoun rather than the neuter pronoun it. We are familiar with the mistakes non-native speakers of a language make. If analysed, these errors almost reflect the lexical and grammatical forms of the person's mother tongue. He/she has literally translated the form from his own language (the source language or customary language) and therefore, his/her speech in a receptor language is unnatural. For example: an advertisement for tourist in Belem-Brazil says: "We glad to you are unforgettable trip by fantastic Marajo' Island" meaning thatwe offer you an unforgettable trip to fantastic Marajo Island. In another place the paper states: Beyond all those things, enjoys of delicious that your proper mind can create. Marajo is inspiration. This statement means that, and above all, enjoys the delights which your own mind will create. Marajo will inspire you. A look at the Portuguese on the other side of the advertisement shows that the unnatural English was the result of following the form of the Portuguese customary language in expressing the idea in the English alien language.

To carry on effective cross-cultural communication, one must discover the meaning of the customary language and use alien language forms which express this meaning in a customary way. With this in mind, giving form and meaning in cross-cultural communication entails:

a) Using the normal language forms of the alien/receptor language.

b) Communicating as much as possible, to the receptor language user the same meaning as that was understood by the customary language user.

c) Maintain the dynamics of the customary language intention. That is, the communication in the alien language should evoke the same response as the customary language did evoke.

\section{Characteristics Of Language Which Affect Communication}

We know that one form may express a variety of meanings. We also know that a single meaning may be expressed in a variety of forms. This implies that even within a simple language, there are great varieties of ways in which form express meaning. But this is true only when a form is used in its primary meaning or function, when there is a one-to-one correlation between form and meaning. The other meanings are secondary or figurative meaning with the understanding that words have these extended meanings and in the same way, grammatical forms have extended usage (secondary and figurative).

This characteristic of "skewing" that is, the diversity or lack of one-to one correlation between form and meaning is the basic reason that makes communication in general a none linear activity, and communication across cultures a complicated task. If there were no skewing, then all lexical items and grammatical forms would have only one meaning, and a literal word-for-word and grammatical structure-for-grammatical structure cross-cultural communication would be possible. But the fact is that, a language is a complex set of skewed relationships between meaning (semantics) and form (lexicon and grammar). Each language has its own distinctive forms for representing meaning to be expressed in another language by a very different form. To use the form of one language literally according to the corresponding form in another language would often change the meaning or at least result in a form which is unnatural. In cross-cultural communication, meaning must therefore have priority over form. It is the meaning which is to be carried over from customary language not the linguistic form. Unless the customary language and the alien language are closely related languages, from the same language family source, it is not likely that there will be much corresponding of form between the customary language and an alien language. A word-for-word transfer that follows closely the form of the customary language or literal transfer is used if one is studying comparative structures of customary language for alien language interlinear usage. A literal cross-communication strategy does not communicate the meaning of the customary language in the alien language. It is generally no more than a string of words and usually unnatural, hard to understand, and may even be quite meaningless or give a wrong meaning in the receptor language. 
It can hardly be called a communication. The goal of cross-cultural communication should be to produce a receptor language communication which is idiomatic; that is, one which has the same cultural meaning as the source language but expressed in the natural form of the receptor cultural language. If it is generally agreed that anything which can be said in one language can be said in another, then, it is possible to effectively communicate across cultures. The goal of cross-cultural communicator should strive to keep the meaning constant whenever necessary, the receptor language form should be adjusted in order to express the source language meaning within its socio-cultural frames. Since language forms express meaning in a particular way, it is often necessary to adjust the form when communicating across different cultures.

\subsection{Literal Versus Idiomatic Communications Across Cultures}

In respect to the fact that a given language has both form and meaning, as discussed earlier, there are two main kinds of communications; one that respects the norms and follows the form of the language culture and is known as straight/literal communication and another kind that uses language specifics in a particular complex manner usually referred to as idiomatic/figurative. While literal communication can be looked upon as common, practised and observed by everyday language users, it is "lexico-gramatically" orientated. Idiomatic communication on the other hand is purely meaning-based and operates at the semantic level of usage necessitating a certain degree of language competence to be operative at this level usually reffered to as idiomatic.

An interlinear communicator is a completely literal lexical user. For some purposes, it is desirable to reproduce the linguistic features of the source text, as for example, in a linguistic study of that language. Although these literal comparative features may be very useful for purposes related to the study of the source language, they are of little help to speakers of the receptor language users. Naturally, if the two languages are related, the literal cognitive macro features can often be understood, since the general grammatical form may be similar. However, the literal choice of lexical items makes the communication foreign within the normative cultural acceptabilities Example: This Bilingual announcement one time in Orly Airport: Madame Odette, passenger with destination Douala, is demanded on the telephone. This English communication is a literal transfer of French lexicogramatical categories as observed in French: Madame Odette, passager à destination de Douala, est demandée au tétéphone. An effective communication in English would be "Ms Odette, passenger for Douala, you are wanted on the phone".

Except for interlinear purpose, a truly literal cross communication is uncommon. Most communicators who tend to cross-communicate literally actually make a partially modified literal communication. They modify the order and grammar enough to use acceptable sentence structures in receptor language. However the lexical items are formulated literally. Occasionally, these items are also changed to improve the communication such to make the result sound natural.

A person who communicates in a modified literal manner will change the grammatical forms when the constructions are obligatory. However if he has a choice, he will follow the forms of the source text even though a different form might be more natural in the receptor language. Idiomatic communications use the natural forms of the receptor language both in the grammatical construction. A truly idiomatic expression in the alien language does not sound like a an alien expression. It sounds like it was frammed originally in the receptor language. Therefore, a good inter-cultural communicator will try to translate idiomatically. This is the goal but nontheless, translations are often a mixture of a literal transfer of the grammatical units along with some idiomatic translation of the meaning of the text. It is not easy to constantly communicate idiomatically. A cross cultural communicator may express some parts of his receptor language communication in very natural forms. On the other hand, communication across cultures falls on a continuum from very literal, to literal, to modified literal, inconsistent mixture, to near idiomatic, to idiomatic; then may even move onto being unduly free. Very literal literal modified literal inconsistant mixture near idiomatic idiomatic unduly free

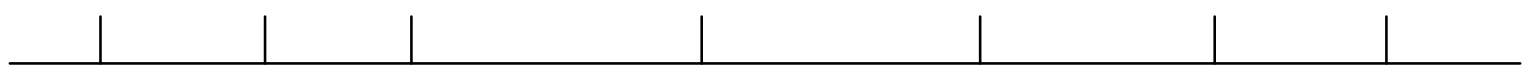

Fig:1 Cross-cultural communication forms

Unduly free communications are not considered acceptable for socio-cultural popurse. When language users communicate in an unduly free mannar, they add extraneous information not in the source culture. This may at times change the meaning of the historical and cultural setting of the source language text, thus cannot be acceptable in crosscultural communication. Sometimes unduly free communications are made for purpose of humour, or to bring about a special response from the receptor language user. 
However, they are not acceptable as normal cultural linguistic features since the emphasis on the meaning they carry is not necessarily that of the source language culture. Communicating across cultures should aim at reproducing in the receptor language an information which communicates the message as the source language but using the natural grammatical and lexical choices of the receptor language in line with the conception that an idiomatic cross-cultural communication reproduces the meaning of the source language (that is the meaning intended by the original communicator) in the natural form of the receptor language though there is always the danger of interference from the form of the source language

\subsection{Modulating Cross-Culturing Grammatical Features}

Parts of speech are language specifics and according to [1], each language has its own division of lexicon into classes such as nouns verbs adjectives etc. different languages will have different classes and subclasses. It will not always be possible to modulate a source language noun with a noun in the receptor language. The pronominal systems vary greatly from language to language and the communicator is obliged to use the forms of the receptor language even though they may have very different meanings than the pronouns of the source language. One may be expected to make a difference between singular and plural persons irrespective of the connons of the source language..

In English for example, the first person plural pronoun we is often used when the real meaning is second person you. The reason for the use of we, is to show empathy and undestanding. The nurse says to the sick child "it's time for us to take our medecines" or the teacher says "we are not going to shout, we will walk quietly to our places" clearly, the pronouns do not refer to the nurse or the teacher but to the children whom she is addressing "you". In communicating these pronouns into another language, a literal gramatical conservation of the first person plural would probably distort the meaning. The user would need to look for the natural way to communicate second person and the feeling of empathy carried by the source language in the receptor language culture. Since grammatical constructions also vary between the source language and the receptor language, the order may be completely reserved.

\subsection{Cross-Communicating Lexical Features}

Each language has its own idiomatic way of expressing meaning through lexical items (words, phrases, etc) for this reason, languages abound in idiom secondary meaning, metaphor, and other figurative meanings.

All languages have idioms - string of words whose meaning is different than the meaning coveyed by the individual words[2]. In English, to say that someone is bullhead means that the person is stubborn. The meaning has little to do with bull or head.

The English language abounds in such idioms.

-Run into debt,

-Stumble into aquintance,

-Glide into intimacy.

These combinations are fixed as to form and their meaning comes from the combination. A literal word for word modulation of these idioms into another language will not make sense. Communicators who want to make a good idiomatic cross-cultural communication often find figures of speech extremely challenging. For example, a literal transfer of the exppression "blind as a bat" might sound really strange in a language where the comparison between a blind man or a person and a bat has never been used as a figure of speech since figures of speech are often based on stories or historical incidents though at times the origin of the figure is no longer apparent.

In the village of Dschang in the West Region of Cameroon, a pig is called « le sous-préfet » or « beau regard ». This has got nothing in common with the adminitrative post of Senior Divisional Officer or a beautiful look, as the statements semiotenously imply. From this analysis, we can admit that two things are necessary for good communication across cultures: an adequate understanding of the customary language (the source language) and an adequate command of the language into which one is communicating across (the receptor language).But considering the complexity of language structures, how can crosscultural communication ever hope to produce an adequate receptor language communication? This can be avoided through the reduction of literalisms in a careful analysis of the source language; by first of all understanding clearly the message to be communicated. And then looking for the equivalent way in which the same message is expressed naturally in the receptor language. It is only through this route that we can achieve a brilliant an adequate cross-culural communication. 


\subsection{Intercultural Communication and Semantics Structure}

Another way to look at form and meaning in language is to think of them as surface structures and deep structures One of the basic assumptions in language dynamics is that there is a valid distinction between the deep (semantic) and the surface (grammatical, lexical, phonological) structures of languages[1]. An analysis of the surface structure of a language does not tell us all that we need to know about it in order to convey the same sense in a different culture. Behind the surface structure is the deep structure- the meaning. It is this meaning that serves as base for communicating across cultures into any language. A second basic assumption is that meaning is structured; it is not just an inaccessible mass[3]. It can be analyzed and represented in ways that are useful in cross cultural communication. Language is not ordered in the way the surface structure must be ordered. It is a network of semantic units and the relations between these units. These units and relations may be represented in various ways.

The conventions which are being examined have been chosen for practical reasons. For from being to agree linguistic theory but rather to present tools which will help in cross cultural communication? Nevertheless, it's important to note that the procedure is based on the two assumptions given above. Semantic structure is more nearly universal then grammatical structure. That is, the type of features and the relationships are essentially the same for all languages. All have meaning components which can be classifies as things, events, attributes or relations, but not all languages have the same surface structure grammatical classes; some have conjunctions, others do not some have prepositional phrases while others don't. Word classes differ from language to language and any concept occurring in any language has its specificity which is cultural bound.

\subsection{The Communication Situation in Code Switching}

It is desirable to make a distinction between those things in language over which the speaker can exercise choice and over which no choice is available to him. The former reflect meaning as many linguists have pointed out, meaning is possible only when a speaker could choose to say something else instead. The latter are the more mechanical components of language, the implication process by which results of the speaker's choices are expressed in a conventional form that permits communication with someone else. The meaning which is chosen will be influenced by the communication situation, that is, by who the speaker is, who the audience is, the traditions of the culture etc. the speaker (or writer) basing this choices on many factors in the communication situation, chooses what he wishes to communicate. Once he has determined the meaning, he is limited to use the forms (grammatical lexical phonological) of the language in which he wishes to make some part more prominent than another, to add some focus to a part of a message. For example, a mother who is angry with her son for not doing his part of the family chores, may desire to tell him to empty the garbage. She has told him to do it before, so he knows it is his duty. She will want to convey all of this meaning. The command to empty the garbage and the emotion she feels about it. To do so, she might not use a surface structure command form but rather a when question: when are you going to empty the garbage? If he had never been asked to do it before, and if she were not angry or exasperated, she would have probably used a command form such as: please empty the garbage for me.

Here because of the emotive meaning being communicated, we have a skewing of form and meaning in that a question form signals a command. Many languages do not use questions in this way, so a different form will be used in adiffrent language situation. However, which-ever form is chosen, it should communicate both the information and the emotion of the source language. Before the form is chosen from the possibilities in the surface structure, socio-linguistic and psycholinguistics matters which affect meaning must be taken into account; and the speaker's, purpose, which in this case is not just to command but to show frustration and insistence, must be included. A question from when indicates this socio-linguistic and psycholinguistic information. Every crosscultural communication is supposed to be faithful to the original. To do this, the communicator must attempt to evoke the same emotional response as the original communication. For the communication to have the same dynamics as the original, it will need to be natural and easy to understand so that the receiver will find it easy to grasp the message, including both the information and the emotional effects contained in the source customary language. Each language communicative art is carried out in a specific historical setting and in a specific cultural setting with a purpose or indent of the author [1].These matters must also be taken into consideration for any effective cross cultural communication. For instance, when ancient manuscripts are being translated into today's languages, there may be tension between trying to be faithful to the historical material and present day context. 
When a source language communication is from a culture very different from the culture of the receptor language, it is always difficult to switch codes in such a way that the result will communicate the same message. That is why communication across cultures occupies an important part in social studies within the context of globalization

\subsection{Cultural Presuppositions and Macro Linguistic Systems}

Cultural presuppositions may sometimes be traced to the linguistic, especially semantic, structures of a language. The most typical case is where comparable words in different languages systems carry strikingly different associations. Generally speaking, westerners are indifferent about sexual matters. They speak plainly when describing sexual affairs and accept such description in so far as they appear as objective fact. African scholars usually talk about sex in terms of imagery or figurative usage that is why communicators need to be fully aware of cultural presuppositions. First, a correct interpretation of the source message relies on an understanding of the relevant features of the source culture. In many cases, however, the presuppositions of a communicator about the source culture may be based upon the realities of his or her own culture. If the source and target cultures differ significantly with respect to the issue at hand, the source message may be wrongly deciphered. This is especially noticed where linguistic ambiguities are involved, as is illustrated in the following The second reason that cultural presuppositions merit attention in cross-cultural communication is that the communicative errors they give rise to are usually more covert and harder to detect than grammatical errors and may therefore cause serious misunderstanding to the target culture. Refrence [4] points out that: "In fact, difficulties arising out of differences of culture constitute the most serious problems in communicating across cultures and have produced the most farreaching misunderstandings among users." These difficulties exist largely because all language users make inferences in some specific socio-cultural context. Inevitably, they will be under the same specific presuppositions proscribed by the culture in which they were brought up. To minimize the chance of language mismatch of the original from the receptor cultural stand point, it is important to constantly be alert about the substructures imposed by the cultural background.

\subsection{General Considerations}

The role of language is not the same in all societies though it often includes the identification or marking of social categories, the maintenance and manipulation of individual social relationships and network as well as various means of effecting social control. This implies that language is socially patterned and plays a dynamic function [5] Furthermore, if social categories are primarily part of the social system then obviously, they are embedded in the language system as it is used to mark them; as such, the use and valuation of the linguistic markers in turn may affect the nature and persistence of the categories themselves. Owing to the fact that societies vary in extent to which communicative behaviour is bound up with the definition of social roles as is the case with many African cultures, not only speaking or writing ability are integral and necessary parts of role understanding and validation.

It is worth noting that in other social context, communicative ability may have little or no significance in terms of role although certain social categories (age and sex) may be marked by characteristic communicative behaviour. The maintenance and manipulation of social relationships are importantly served by getting events in many communities and many include the way of expressing certain behaviours or interpreting certain actions ranging from formal to non-formal interactions. What is considered "appropriated" interactional behaviour within the community is largely determined by a social categorization. Ethno-translation harnesses these categories in order to place a translation within its socio-cultural confines (a network of existing relationship) through the choice of words.

Whatever linguistic community, the how to saymatters a lot because the communicative function is subject to conventionality, as it shapes and orients every thought and action hence making language the strongest control form in any given society in all aspects. Language also serves in social control by the way it is used in politics. Many political leaders have explored the dimension of the effect of patterns of communication on political thought and activity extensively and one may not be wrong to say that the intentions of these people can be inferred by the implications of the type of speech they use. Reference [3]distinguishes between formal language and informal language or formal speech situations and every day speech situations and their relative degree of social control. 
He points out clearly in his analysis that: "when a speech event, if formalized, there are fewer options for participants, thus, as language becomes more formalized, more social control is exerted on participants in a communicative art". A fundamental hazel with cultural communicative translation lies at the level of sociocultural stratifications. We abjure the facts that in formalizing a situation, the prepositional context and the logic, are essentially removed aspects. Yet the logic and this prepositional context are meaning-bound. On the other hand, when formalized, it is accepted by the society because it is the right thing to say, and not because it is true or false. For instance, the phenomenon of homosexuality is gradually being accepted in our linguistic culture but still to be accepted in are values. Due to the fact that most African speech communities are ritual oriented, they use highly formalized language patterns and in societies where there are more emphasis on ritual events, there is less freedom and more direct control than in societies where there is less emphasis on ritual. This is the case with Countries like China, Japan and India. The control may be in both directions, controlling those in authority as well as those being governed. If the social community is a closed type, ritual events are much more likely to be important than to an open type.

\subsection{Conclusion}

Cross-cultural communication must spell out these distinctions and sort to make for when the context is highly coded, that is, roles that are rigidly contextualised with a small range of alternative form. It also has to recognize strength of an elaborate code in a less structured context where meanings must be made more explicit and speakers have a wide range of choice. The restricted code serves the social function of control as well as communication, and creates solidarity. The relationship of social structures and communication patterns suggest dimensions for a typology of speech communities which might allow the analyses and display of patterns at a more abstract level and thus contribute to the general theory of cross-cultural communication principles. All of these are related to the distinction [6] make in the types of interaction that takes place in primitive groups and literate societies because of different levels of shared experience. These differences exist in form and context, therefore, to postulate that communicative patterns do not have socio-cultural bearings would be an over simplification of the relation between language and distinctive linguistic cultures. From this point, it could be recognized that the only reasonable basis from which to assert, either theoretically or practically, the convertibility of semantic features of a communicative art across different linguistic communities are the cultural specifics. Where communication is an informing objective of the exercise, some measure at least of adaptation is inescapable. Such transubstantiation of the literal original will clearly arise from the need to negotiate culture specific icons, motifs, discourse, speech - patterns, and the like. But also, more intangibly from the requirement to ensure that the impact and range of the meanings implicit in the original language culture, and which are only fully decoded through pragmatics of communication, may be similarly decoded in the receptor language culture.

\section{References}

Quynh Lê and Thao Lê (2011).Linguistic Diversity and Cultural Identity: A Global Perspective， Nova Science Publishers, Inc. New York

Harbans, S. (2008) Signposts to literacy for sustainable Development. UNESCO institute for lifelong learning

Hopkins, R. (2013) African cultural consciousness and African-centered Historiography as for Wilson's New world Order Journal of Pan African studies, Vol.6 N² 2, July

preconditions

2013

Brière, E.(1988). "In Search of Cultural Equivalence: Translation of Camara Laye's L'Enfant Noire “. Translation review 27

Mead, R. (2010) Cross Cultural Management Communication. Courier International Ltd. Essex Ouana, Simon,S.(1992) "The language of cultural difference",Concordian University Québec 